\title{
Qualidade dos ovos frescos e armazenados em função do tempo de permanência nos ninhos em sistema cage-free
}

Quality of fresh and stored eggs related to the permanence time in nest boxes from cage-free aviary housing system

Calidad de los huevos frescos y almacenados en función del tiempo de permanencia en cajas nidos del sistema cage-free

Daniel Rodrigues Dutra

ORCID: https://orcid.org/0000-0001-5435-243X Universidade Estadual Paulista, Brasil

E-mail: danielrdutra@hotmail.com

Gustavo Camacho Paschoalin

ORCID: https://orcid.org/0000-0001-8468-0071 Instituto de Zootecnia, Brasil

E-mail: gustavocpaschoalin@gmail.com

Rodrigo Alves de Souza

ORCID: https://orcid.org/0000-0002-0018-6971

Universidade de São Paulo, Brasil

E-mail: rodrigo.zootecnista@gmail.com

Juliana Lolli Malagoli de Mello

ORCID: https://orcid.org/0000-0003-4648-1412

Universidade Estadual Paulista, Brasil

E-mail: julianalolli@zootecnista.com.br

Aline Giampietro-Ganeco

ORCID: https://orcid.org/0000-0002-6966-1902

Universidade de São Paulo, Brasil

E-mail: algiamp@yahoo.com.br

Fábio Borba Ferrari

ORCID: https://orcid.org/0000-0002-9339-0911 Universidade Estadual Paulista, Brasil E-mail: fbf_zoo@hotmail.com

Pedro Alves Souza

ORCID: https://orcid.org/0000-0002-2657-2045 Universidade Estadual Paulista, Brasil E-mail: p.souza@unesp.br

Hirasilva Borba

ORCID: https://orcid.org/0000-0001-7057-3945 Universidade Estadual Paulista, Brasil

E-mail: hirasilva.borba@unesp.br

Carla Cachoni Pizzolante

ORCID: https://orcid.org/0000-0002-4992-5982 Instituto de Zootecnia, Brasil E-mail: carla@iz.sp.gov.br

\section{Resumo}

O objetivo deste estudo foi investigar se a permanência dos ovos cage-free nos ninhos compromete sua qualidade interna. Foram distribuídos 660 ovos de poedeiras comerciais Isa Brown, com 31 semanas, em dois estudos independentes. No estudo 1, foi avaliada a qualidade de 180 ovos frescos submetidos a diferentes tempos de permanência no ninho (0h, 2h, 4h, 6h). Analisou-se peso dos ovos, altura de albúmen, Unidade Haugh e Índice Gema. No estudo 2, foram armazenados 480 ovos em esquema fatorial 4 x 5 [tempo de permanência no ninho ( $0 \mathrm{~h}, 2 \mathrm{~h}$, $4 \mathrm{~h}$, 6h) vs período de armazenamento $(0,7,14,21$ e 28 dias)]. Foram avaliados altura de albúmen, Unidade Haugh, Índice Gema, pH de gema e albúmen, oxidação lipídica e perda de peso dos ovos. Observaram-se alterações significativas para Unidade Haugh e altura de albúmen em ovos frescos, à medida que os ovos permaneciam no ninho, com menores valores $(\mathrm{P}<0,05)$ 6h pós-postura. Já em ovos armazenados, houve interação significativa entre o tempo de permanência no ninho e o período de armazenamento para Unidade Haugh, altura de albúmen, pH de gema e oxidação lipídica. Ao longo do armazenamento houve perda de qualidade, com menor $(\mathrm{P}<0,05)$ Índice Gema e maior $(\mathrm{P}<0,05)$ perda de peso aos 28 dias. $\mathrm{O} \mathrm{pH}$ do albúmen foi superior $(\mathrm{P}<0,05)$ do $7^{\circ}$ ao $28^{\circ}$ dia de armazenamento. 
Conclui-se, portanto, que ovos cage-free sejam coletados o mais breve possível, preferencialmente até 4 horas após a postura, pois suas perdas em qualidade são constantes ao longo de sua permanência no ninho, sendo refletidas durante o armazenamento dos ovos.

Palavras-chave: Albúmen; Armazenamento; Galinhas livres de gaiola; Gema; Poedeiras.

\begin{abstract}
The aim of this study was to investigate whether the permanence of cage-free eggs in the nests compromises their internal quality. 660 commercial Isa Brown laying eggs, 31 weeks old, were distributed in two independent studies. In study 1, the quality of 180 fresh eggs submitted to different permanence times in the nest $(0 \mathrm{~h}, 2 \mathrm{~h}, 4 \mathrm{~h}, 6 \mathrm{~h})$ was evaluated. Egg weight, albumen height, Haugh Unit and Yolk Index were analyzed. In study 2, 480 eggs were stored in a 4 x 5 factorial scheme [length of permanence in the nest $(0 \mathrm{~h}, 2 \mathrm{~h}, 4 \mathrm{~h}, 6 \mathrm{~h})$ vs storage period $(0,7,14,21$ and 28 days)]. Albumen height, Haugh Unit, Yolk Index, yolk and albumen pH, lipid oxidation and egg weight loss were evaluated. Significant changes were observed for Haugh Unit and albumen height in fresh eggs, as the eggs remained in the nest, with lower values $(\mathrm{P}<0.05) 6 \mathrm{~h}$ post-laying. In stored eggs, there was significant interaction between the permanence time in the nest and the storage period for Haugh Unit, albumen height, yolk pH and lipid oxidation. During storage there was loss of quality, with lower $(\mathrm{P}<0.05)$ Yolk Index and greater $(\mathrm{P}<0.05)$ weight loss at 28 days. The albumen $\mathrm{pH}$ was higher $(\mathrm{P}<0.05)$ from the 7 th to the 28th day of storage. It is concluded, therefore, that cage-free eggs must be collected as soon as possible, preferably up to 4 hours after laying, once their losses in quality are constant throughout their permanence in the nest, being reflected during the storage of the eggs.
\end{abstract}

Keywords: Albumen; Cage-free hens; Laying hens; Storage; Yolk.

\title{
Resumen
}

El objetivo de este estudio fue investigar si la permanencia de los huevos cage-free en los nidos compromete su calidad interna. Para ello se distribuyeron 660 huevos de gallinas ponedoras industriales Isa Brown, de 31 semanas de edad, en dos estudios independientes. En el estudio 1 se evaluó la calidad de 180 huevos frescos sometidos a diferentes tiempos de permanencia en el nido ( $0 \mathrm{~h}, 2 \mathrm{~h}, 4 \mathrm{~h}, 6 \mathrm{~h})$. Se analizaron el peso del huevo, la altura de la albúmina, la Unidad Haugh y el Índice de Yema. En el estudio 2, se almacenaron 480 huevos en un esquema factorial 4 × 5 [tiempo de permanencia en el nido (0h, 2h, 4h, 6h) vs período de almacenamiento (0, 7, 14, 21 y 28 días)]. Se evaluaron la altura de la albúmina, la Unidad Haugh, el Índice de Yema, el pH de la yema y de la albúmina, la oxidación de lípidos y la pérdida de peso del huevo. Se observaron diferencias significativas para la Unidad Haugh y la altura de la albúmina en los huevos frescos, observándose que los huevos que permanecieron en el nido durante mayor tiempo $(6 \mathrm{~h})$ presentaron los valores más bajos $(\mathrm{P}<0.05)$. Con relación a los huevos almacenados, hubo interacción significativa entre el tiempo de permanencia en el nido y el período de almacenamiento para la Unidad Haugh, la altura de la albúmina, el pH de la yema y la oxidación de lípidos. Durante el almacenamiento hubo pérdida de calidad, con menores $(\mathrm{P}<0.05)$ Índices de Yema y mayores $(\mathrm{P}<0.05)$ pérdidas de peso a los 28 días. El pH de la albúmina fue mayor $(\mathrm{P}<0.05)$ desde el día 7 hasta el día 28 de almacenamiento. Se concluye, por lo tanto, que los huevos cage-free sean recolectados lo más antes posible, preferiblemente, hasta 4 horas después de la puesta, ya que la pérdida de calidad es constante durante su permanencia en el nido, reflejándose durante el almacenamiento de los huevos.

Palabras clave: Albúmen; Almacenamiento; Gallinas libres de jaulas; Yema; Ponederas.

\section{Introdução}

A criação de poedeiras comerciais em sistemas de bateria fez com que emergisse uma das maiores discussões em relação ao bem-estar animal nos últimos anos em função do reduzido espaço disponível às aves e da ausência de estímulo ambiental nas gaiolas, limitando seus movimentos e a expressão de comportamentos naturais inerentes à espécie (Alves et al., 2007).

Na União Europeia, o sistema de produção de aves em gaiolas foi banido em 2012, como resultado da Diretiva 1999/74/EC que forçou a adoção de sistemas alternativos para toda a cadeia produtiva de ovos, os chamados non-cage systems. Nos Estados Unidos, o Estado da Califórnia, por meio da Proposição 2/2008, também baniu a utilização dos sistemas de gaiolas em bateria. Como consequência, grandes redes de supermercados e players da indústria de alimentos também têm estabelecido prazos para deixarem de comercializar ovos provenientes de aves criadas em gaiolas.

Dentre os non-cage systems, merece destaque o sistema cage-free onde as aves são criadas livres de gaiolas, em galpões fechados, com total liberdade para expressarem seus comportamentos naturais, como a postura de ovos em ninhos, banhos de areia, possibilidade de se empoleirar, ciscar, bater e esticar suas asas (Silva et al., 2006). Entretanto, sabe-se que o 
modelo de produção empregado, a frequência de coleta e o tempo de armazenamento dos ovos podem comprometer a qualidade do produto final (Brito et al., 2020; Dutra et al., 2021; Englmaierová et al., 2014; Scott \& Silversides, 2000).

A qualidade interna dos ovos tem sido diretamente relacionada aos aspectos da gema, dimensionamento da câmara de ar, ausência de manchas de sangue e, principalmente, pela consistência, altura e diâmetro do albúmen (Mendes et al., 2014), cujas alterações são de fácil mensuração, representando bons indicadores da qualidade interna dos ovos (Alleoni \& Antunes, 2001).

Os sistemas alternativos apresentam maiores níveis de microrganismos e poeiras presentes no ambiente em relação às gaiolas convencionais ou enriquecidas, oferecendo maior risco de contaminação e comprometimento da qualidade interna dos ovos (Rodenburg et al., 2005; Shepherd et al., 2015). Em função desta alta carga de sujidades, o Protocolo de Boas Práticas na Produção de Ovos da União Brasileira de Avicultura (UBA, 2008) recomenda que a coleta de ovos seja realizada pelo menos quatro vezes ao dia, de forma a assegurar sua qualidade. No entanto, as recomendações para sistemas alternativos necessitam de melhor elucidação científica.

Além disso, vários atributos de qualidade do albúmen e de gema são perdidos com o armazenamento prolongado dos ovos, sobretudo pela perda de água e de dióxido de carbono (Leandro et al., 2005), contribuindo para a deterioração do ovo ao longo do tempo (Alleoni \& Antunes, 2001); principalmente em países como o Brasil, onde o armazenamento dos ovos comercializáveis sob refrigeração não é obrigatório, sendo acondicionados em temperatura ambiente do momento da postura até sua distribuição final.

Dessa forma, este estudo teve como objetivo avaliar a qualidade interna de ovos provenientes do sistema cage-free, frescos e armazenados por até 28 dias em temperatura ambiente, em função do tempo de permanência dos ovos nos ninhos.

\section{Metodologia}

Um total de 660 ovos foram coletados por três dias, em granja comercial localizada em Ipeúna, SP, provenientes de um único lote de poedeiras Isa Brown, com 31 semanas de idade. As aves foram criadas livres de gaiolas em sistema cage-free, com livre acesso aos ninhos, poleiros e à cama do galpão constituída por palha de arroz. O galpão possuía telas laterais, cortinas plásticas, ventiladores, bebedouros pendulares, comedouros automáticos e ninhos de madeira forrados com palha de arroz, na proporção de um ninho para sete aves.

Foram definidos quatro tempos de coleta, baseados no tempo de permanência dos ovos nos ninhos: 0h imediatamente após a postura; $2 \mathrm{~h}$ - duas horas pós-postura; $4 \mathrm{~h}$ - quatro horas pós-postura; $6 \mathrm{~h}$ - seis horas pós-postura. Às 7:00 todos os ovos presentes nos ninhos eram recolhidos, seguindo o fluxograma de produção da granja, para, então, serem procedidas as coletas experimentais dentro de cada tempo avaliado. A temperatura e a umidade relativa do galpão foram registradas com a utilização de um termo-higrômetro.

A partir daí foram realizados dois estudos independentes, por meio do método quantitativo experimental (Pereira et al., 2018), tal qual aplicado por Dutra et al. (2021), ao avaliarem a qualidade interna de ovos de perdizes brasileiras durante 28 dias de armazenamento. No estudo 1, objetivou-se avaliar a qualidade interna de 180 ovos frescos, distribuídos em delineamento inteiramente casualizado, em função de seus diferentes tempos de permanência no ninho ( $0 \mathrm{~h}, 2 \mathrm{~h}, 4 \mathrm{~h}$ e $6 \mathrm{~h}$ ), composto por 3 repetições de 15 ovos/tempo. Foram aferidas as temperaturas médias dos ovos e dos ninhos em cada tempo de coleta, por meio do termômetro infravermelho Fluke® modelo 59 MAX. Imediatamente após as coletas, foram avaliados o peso do ovo, altura de albúmen, Unidade Haugh e Índice Gema na própria granja.

No estudo 2, avaliou-se a qualidade interna de 480 ovos armazenados por até 28 dias, em função do tempo de permanência dos ovos no ninho. Para execução deste estudo foi utilizado delineamento inteiramente casualizado em esquema fatorial $4 \times 5$ [tempo de permanência no ninho ( $0 \mathrm{~h}, 2 \mathrm{~h}, 4 \mathrm{~h}$ e $6 \mathrm{~h}) v s$ período de armazenamento $(0,7,14,21 \mathrm{e} 28$ dias)], composto 
por 4 repetições de 6 ovos/período.

Imediatamente após cada coleta dos ovos do estudo 2, estes foram identificados e acondicionados em embalagens plásticas com capacidade para 12 ovos. Visando simular uma situação real de transporte entre o entreposto e o supermercado, as embalagens plásticas foram acondicionadas em caixas de papelão contendo 30 embalagens cada e transportadas em temperatura ambiente até o Laboratório de Análise de Alimentos de Origem Animal, do Departamento de Tecnologia da Faculdade de Ciências Agrárias e Veterinárias da Universidade Estadual Paulista, campus de Jaboticabal, SP, onde foram realizadas as análises subsequentes.

As embalagens contendo os ovos permaneceram armazenadas em sala com temperatura de $22^{\circ} \mathrm{C} \pm 3{ }^{\circ} \mathrm{C}$ e umidade relativa média de 37\% por até 28 dias. Ao final de cada período de armazenamento (0, 7, 14, 21 e 28 dias), foram avaliados a perda de peso dos ovos, altura de albúmen, Unidade Haugh, Índice Gema, pH da gema, pH de albúmen e oxidação lipídica.

Todos os ovos foram inicialmente pesados em balança analítica digital com precisão de $0,01 \mathrm{~g}$. Para verificar a perda de peso durante o armazenamento (estudo 2), os ovos foram novamente pesados ao final de cada período experimental ( 7,14 , 21 e 28 dias). A perda de peso foi calculada em porcentagem e obtida pela diferença entre o peso inicial e final dos ovos.

Após a pesagem, os ovos foram quebrados sobre mesa de vidro especial, plana e nivelada. A altura de albúmen foi mensurada com a utilização de micrômetro (Egg Quality Micrometer) e realizadas três medições no ponto médio entre a extremidade da gema e a extremidade externa do albúmen denso. A média dos três pontos da altura do albúmen foi calculada e os valores de unidade Haugh obtidos segundo a equação: $\mathrm{UH}=100 \log (\mathrm{h}+7,57-1,7 \mathrm{p} 0,37)$, onde "h" refere-se à altura do albúmen (mm) e "p" ao peso do ovo (g) (Card \& Nesheim, 1978).

O Índice Gema foi obtido pela relação entre altura da gema (AG) e diâmetro da gema (DG), (IG = AG/DG). A altura da gema foi mensurada por meio do supracitado micrômetro e o seu diâmetro por paquímetro digital Caliper (0-150 mm).

Para determinação do $\mathrm{pH}$ da gema e do albúmen, ambos foram separados, acondicionados em frascos coletores e suavemente homogeneizados para proceder com a aferição por meio do peagâmetro digital Testo® 205.

A oxidação lipídica foi avaliada segundo o método proposto por Vyncke (1970) que avalia as substâncias reativas ao ácido tiobarbitúrico (TBARS), expressas em quantidade de malonaldeído por quilograma de amostra, ao início e ao fim de cada período de armazenamento $(0,7,14,21$ e 28 dias). Foram utilizados $10 \mathrm{~g}$ de ovos in natura, pesados em tubos falcon com capacidade para $50 \mathrm{~mL}$, acrescentados $25 \mathrm{~mL}$ de ácido tricloroacético 7,5\% e homogeneizados em Turrax (7000 rpm) por 90 segundos. O homogeneizado foi filtrado e, em seguida, $5 \mathrm{~mL}$ do filtrado foram dispostos em tubos de ensaio, adicionando-se 5 $\mathrm{ml}$ de solução de ácido tiobarbitúrico 0,02M. Os tubos foram tampados e aquecidos em banho-maria $\left(98{ }^{\circ} \mathrm{C}\right)$ por 40 minutos. Foi realizada leitura das amostras em espectrofotômetro com comprimento de onda definido em $538 \mathrm{~nm}$.

Os resultados de ambos os estudos foram analisados pelo procedimento GLM do SAS (SAS, 2002), submetidos à análise de variância e comparados pelo teste Tukey com significância definida em $\mathrm{P}<0,05$.

\section{Resultados e Discussão}

Os valores médios obtidos no estudo 1 para peso do ovo, altura de albúmen, Unidade Haugh e Índice Gema para ovos coletados no ninho, em diferentes tempos pós-postura, são apresentados na Tabela 1. 
Tabela 1. Médias de peso do ovo (g), altura do albúmen (mm), Unidade Haugh (UH) e Índice Gema (IG) de ovos cage-free coletados com diferentes tempos de permanência no ninho após a postura.

\begin{tabular}{ccccc}
\hline $\begin{array}{c}\text { Permanência do ovo } \\
\text { no ninho }\end{array}$ & Peso do ovo $(\mathbf{g})$ & Altura de albúmen $(\mathbf{m m})$ & UH & IG \\
\hline Oh & 59,14 & $11,36^{\mathrm{a}}$ & $104,90^{\mathrm{a}}$ & 0,57 \\
$2 \mathrm{~h}$ & 57,35 & $10,71^{\mathrm{b}}$ & $102,51^{\mathrm{bb}}$ & 0,52 \\
$4 \mathrm{~h}$ & 59,71 & $10,26^{\mathrm{bc}}$ & $100,20^{\mathrm{bc}}$ & 0,51 \\
6h & 59,57 & $9,88^{\mathrm{c}}$ & $98,62^{\mathrm{c}}$ & 0,52 \\
\hline CV $(\%)$ & 8,99 & 11,17 & 4,98 & 27,1 \\
PR>F & 0,1305 & $<0,0001$ & $<0,0001$ & 0,1118 \\
\hline
\end{tabular}

Médias seguidas por letras diferentes na coluna diferem significativamente entre si pelo teste de Tukey $(\mathrm{P}<0,05)$.

Fonte: Autores.

Ao avaliar a qualidade interna dos ovos frescos, coletados em diferentes tempos de permanência no ninho após a postura, não foi observada variação $(\mathrm{P}=0,1305)$ de peso ou diferença $(\mathrm{P}=0,1118)$ quanto ao Índice Gema dos ovos cage-free (Tabela 1).

De acordo com o manual da linhagem, o peso médio esperado para ovos de poedeiras com 31 semanas são 63 gramas (Isa Hendrix Genetic Company, 2007), valor próximo aos encontrados neste estudo.

Foi verificada redução $(\mathrm{P}<0,0001)$ da altura do albúmen à medida que os ovos permaneceram no ninho por mais tempo. Percebeu-se que esta variável foi significativamente afetada já nas primeiras duas horas de permanência dos ovos nos ninhos, ressaltando-se que as reações que resultam na perda de qualidade do albúmen começam a ocorrer imediatamente após a postura, com menor $(\mathrm{P}<0,05)$ altura verificada após 6 horas de permanência no ninho.

A Unidade Haugh também apresentou diferenças significativas entre os tempos. O maior valor foi obtido para ovos que não permaneceram no ninho (0h), enquanto o menor valor foi observado para ovos que permaneceram por 6 horas no ninho.

A queda dos valores observados para essas variáveis pode ser atribuída, principalmente, aos fatores relacionados à ambiência, pois quanto mais tempo os ovos permanecem nos ninhos, mais tempo estão sujeitos às condições ambientais adversas, como a variação de temperatura e umidade relativa interna do galpão, alternância de temperatura dos ninhos, além do contato direto com a superfície corporal das aves, quando estas entram novamente nos ninhos e se posicionam sobre os ovos, aquecendo-os.

Os efeitos do clima tropical, como temperatura e umidade relativa do ar, são fatores importantes que interferem na qualidade dos ovos (Leandro et al., 2005). A temperatura ambiente elevada favorece as reações físico-químicas que ocorrem dentro dos ovos, logo após a postura, resultando no processo de degradação do albúmen, devido à desnaturação proteica e à ação do ácido carbônico (H2CO3) presente nos ovos; o que resulta na fluidificação do albúmen, com diminuição de sua altura, devido à perda de $\mathrm{CO}_{2}$ para o ambiente e consequente aumento do seu pH (Cedro et al., 2010; Davis \& Stephenson, 1991; Morais et al., 1997). Quanto mais alta a temperatura a que os ovos são submetidos, menor será a solubilidade do $\mathrm{CO}_{2}$, e mais rápida será sua perda para o ambiente (Santos, 2009b). O que pode ser claramente justificado pela elevação da temperatura e queda da umidade relativa do ar (UR) ao longo do dia, coincidindo com o aumento do tempo de coleta, conforme pode ser observado nas Figuras 1 e 2, onde os ovos que permaneceram mais tempo nos ninhos (4 e 6 horas) estiveram sujeitos a temperaturas ambientais mais elevadas e a menores índices de UR, quando comparados aos ovos que permaneceram somente 2 horas ou menos nos ninhos, nas horas mais frescas do dia. 
Figura 1. Temperatura do galpão no momento da coleta dos ovos.

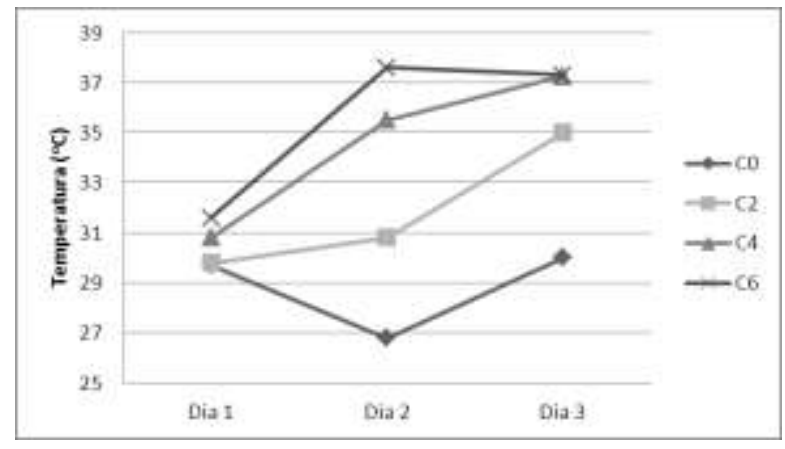

Fonte: Autores.
Figura 2. Umidade relativa do galpão no momento da coleta dos ovos.

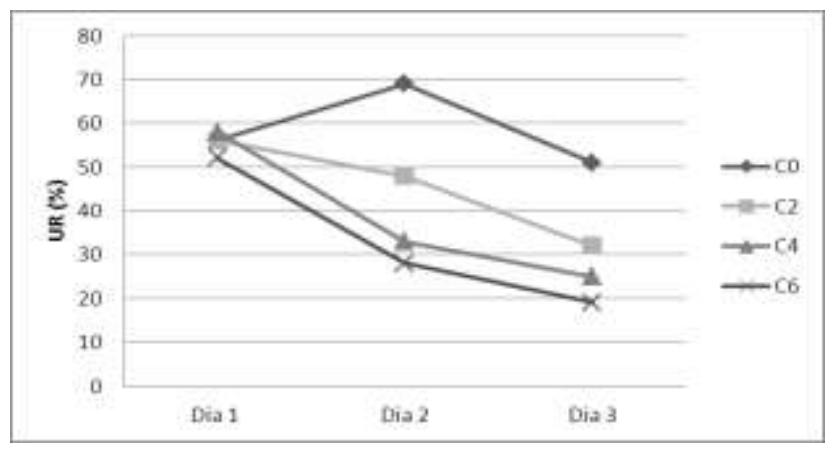

Fonte: Autores.

Essa maior exposição a condições ambientais adversas resultou em maiores temperaturas individuais dos ovos no momento da coleta, e podem explicar as reduções observadas nos resultados obtidos para altura de albúmen e Unidade Haugh (Tabela 1). Haja visto que os ovos coletados nos tempos $0 \mathrm{~h}, 2 \mathrm{~h}, 4 \mathrm{~h}$ e $6 \mathrm{~h}$ pós-postura apresentaram temperatura média de $35^{\circ} \mathrm{C}$, $31,8^{\circ} \mathrm{C}, 32,2^{\circ} \mathrm{C}$ e $33,8^{\circ} \mathrm{C}$, respectivamente, enquanto os ninhos apresentaram temperatura média de $29,7^{\circ} \mathrm{C}, 31,5^{\circ} \mathrm{C}, 32,1^{\circ} \mathrm{C}$ e $33,6^{\circ} \mathrm{C}$ após $0 \mathrm{~h}, 2 \mathrm{~h}, 4 \mathrm{~h}$ e $6 \mathrm{~h}$ pós-postura, respectivamente.

O Programa de Controle de Qualidade para ovos de consumo, elaborado pelo Departamento de Agricultura dos Estados Unidos, classifica como ovos de qualidade excelente (AA) aqueles que apresentam valores de Unidade Haugh superiores a 72, qualidade alta (A) aqueles com valores entre 60 e 72 e de qualidade inferior (B) os ovos que apresentem valores de Unidade Haugh inferiores a 60 (USDA, 2000). Isso demonstra que, apesar de terem sido observadas perdas significativas na Unidade Haugh, os valores encontrados para todos os tempos de permanência no ninho, permitiram classificar os ovos como AA, ou seja, de excelente qualidade. Os altos valores encontrados para Unidade Haugh e altura de albúmen neste estudo podem ser atribuídos, ainda, ao fato de as aves serem jovens e estarem no pico de postura.

Para o IG não houve diferenças significativas entre os tempos de permanência no ninho (Tabela 1), demonstrando que não houve perda do frescor dos ovos. Os valores observados em todos os tempos de coleta se encontraram acima dos descritos por Souza (1997), que atribui aos ovos frescos valor de IG entre 0,40 e 0,42, e próximos daqueles descritos por Morais (1997), que classifica como frescos os ovos com IG entre 0,30 e 0,50 .

Já os valores médios obtidos no estudo 2 para Unidade Haugh, Índice Gema, altura de albúmen, e peso do ovo, em função do tempo de permanência dos ovos no ninho e do período de armazenamento estão dispostos na Tabela 2. 
Tabela 2. Médias corrigidas ( \pm desvio-padrão) obtidas para Unidade Haugh (UH), Índice Gema (IG), altura de albúmen e perda de peso (PP) de ovos cage-free coletados no ninho até 6 horas após a postura e armazenados por até 28 dias.

\begin{tabular}{|c|c|c|c|c|}
\hline $\begin{array}{c}\text { Permanência do ovo } \\
\text { no ninho }\end{array}$ & UH & IG & $\begin{array}{l}\text { Altura de Albúmen } \\
(\mathrm{mm})\end{array}$ & $\mathbf{P P}(\%)$ \\
\hline $\mathrm{Oh}$ & $63,44 \pm 0,787$ & $0,37 \pm 0,004^{\mathrm{A}}$ & $5,21 \pm 0,081$ & $3,39 \pm 0,111$ \\
\hline $2 \mathrm{~h}$ & $60,88 \pm 0,787$ & $0,37 \pm 0,004^{\mathrm{A}}$ & $4,89 \pm 0,081$ & $3,24 \pm 0,111$ \\
\hline $4 \mathrm{~h}$ & $57,51 \pm 0,808$ & $0,35 \pm 0,004^{\mathrm{B}}$ & $4,61 \pm 0,083$ & $3,27 \pm 0,111$ \\
\hline $6 \mathrm{~h}$ & $55,66 \pm 0,791$ & $0,35 \pm 0,004^{\mathrm{B}}$ & $4,40 \pm 0,081$ & $3,49 \pm 0,111$ \\
\hline \multicolumn{5}{|l|}{ Período de armazenamento } \\
\hline 0 dia & $101,27 \pm 0,882$ & $0,51 \pm 0,004^{\mathrm{A}}$ & $10,47 \pm 0,091$ & $0,00^{\mathrm{E}}$ \\
\hline 7 dias & $59,46 \pm 0,882$ & $0,38 \pm 0,004^{\mathrm{B}}$ & $4,15 \pm 0,091$ & $2,19 \pm 0,124^{\mathrm{D}}$ \\
\hline 14 dias & $55,13 \pm 0,877$ & $0,35 \pm 0,004^{\mathrm{C}}$ & $3,74 \pm 0,091$ & $3,59 \pm 0,124^{\mathrm{C}}$ \\
\hline 21 dias & $45,97 \pm 0,892$ & $0,30 \pm 0,004^{\mathrm{D}}$ & $3,06 \pm 0,092$ & $4,69 \pm 0,124^{\mathrm{B}}$ \\
\hline 28 dias & $35,03 \pm 0,902$ & $0,26 \pm 0,004^{\mathrm{E}}$ & $2,46 \pm 0,092$ & $6,27 \pm 0,124^{\mathrm{A}}$ \\
\hline Fonte de variação & \multicolumn{4}{|c|}{ Níveis de significância } \\
\hline Permanência no ninho & $<0,0001$ & $<0,0001$ & $<0,0001$ & 0,3773 \\
\hline Armazenamento & $<0,0001$ & $<0,0001$ & $<0,0001$ & $<0,0001$ \\
\hline $\begin{array}{c}\text { Permanência no ninho } \mathrm{x} \\
\text { Armazenamento }\end{array}$ & 0,0049 & 0,0897 & $<0,0001$ & 0,3814 \\
\hline
\end{tabular}

Médias seguidas por letras diferentes na coluna diferem significativamente entre si pelo teste de Tukey $(\mathrm{P}<0,05)$.

Fonte: Autores.

Analisando os resultados do estudo 2, observou-se que não houve interação $(\mathrm{P}>0,05)$ entre o tempo de permanência dos ovos nos ninhos e o período de armazenamento para as variáveis Índice Gema (IG) e perda de peso (PP). Porém, ocorreu interação significativa para Unidade Haugh (UH) e altura de albúmen entre o tempo de permanência no ninho e os períodos de armazenamento.

Quando avaliados individualmente, tanto o tempo que os ovos permaneceram nos ninhos, quanto o período de armazenamento, influenciaram significativamente o IG dos ovos avaliados, resultando em suave declínio da qualidade da gema ao longo do armazenamento e naqueles ovos que permaneceram nos ninhos por quatro horas ou mais. Diferentemente do estudo 1, que não houve significância para o IG, a perda em qualidade da gema observada no estudo 2 pode ter sido consequência das altas temperaturas registradas no interior do galpão, nos dias mais quentes de coleta (Figura 1). É sabido que altas temperaturas podem resultar em estiramento e aumento da fragilidade e permeabilidade da membrana vitelínica e, consequentemente, acelerar o trânsito da água do albúmen para a gema, que possui maior pressão osmótica, fazendo com que esta perca sua forma esférica e se torne mais alongada e achatada, ocasionando redução no Índice Gema, já que este é baseado na relação entre a altura e o diâmetro da gema, ou seja, quanto menor a altura e maior o diâmetro, menor será o valor de IG (Siebel \& Souza-Soares, 2004; Jones et al., 2002).

Os valores de IG encontrados para ovos do dia 0 (Tabela 2) também são superiores àqueles descritos por Souza (1997) e por Morais et al. (1997) para caracterizarem ovos frescos, demonstrando alta qualidade no momento da postura. Levando-se em consideração os valores de IG estabelecidos por Morais et al. (1997) para classificação de ovos frescos (0,30-0,50), pode-se inferir que a qualidade das gemas dos ovos cage-free se manteve estável até os 21 dias de armazenamento.

Com relação à perda de peso dos ovos, não foram observadas influência do período de exposição dos ovos ao ninho $(\mathrm{P}>0,05)$, mas, sim, do tempo de armazenamento $(\mathrm{P}<0,05)$, com o mais alto valor observado aos 28 dias. De acordo com Santos (2009a), a perda de peso dos ovos durante o armazenamento é decorrente da perda de água do albúmen para a gema, e deste para o ambiente, através das porosidades presentes na casca dos ovos. Além disso, o mesmo autor afirma que a altura do 
albúmen denso e o Índice Gema são fatores de qualidade interna que possuem relação com a perda de peso, pois a dissociação de elementos pertencentes a estas estruturas, associados à evaporação de água para o meio externo, promovem a diminuição do peso do ovo. Esse processo é diretamente influenciado por fatores externos como a alta temperatura, circulação de ar e UR no ambiente em que os ovos são armazenados (Palmer, 1972).

O desdobramento das interações entre o tempo de permanência dos ovos nos ninhos e o período de armazenamento para os parâmetros Unidade Haugh e altura de albúmen podem ser visualizados na Tabela 3.

Tabela 3. Desdobramento das interações ( \pm desvio-padrão) entre o tempo de permanência dos ovos cage-free no ninho e o período de armazenamento para Unidade Haugh (UH) e altura de albúmen.

\begin{tabular}{|c|c|c|c|c|}
\hline \multirow{2}{*}{ UH } & \multicolumn{4}{|c|}{ Permanência do ovo no ninho } \\
\hline & $\mathbf{0 h}$ & $2 \mathrm{~h}$ & $4 h$ & $6 \mathrm{~h}$ \\
\hline \multicolumn{5}{|c|}{ Período de armazenamento } \\
\hline 0 dia & $106,80 \pm 1,746^{\mathrm{Aa}}$ & $102,04 \pm 1,746^{\text {Aab }}$ & $99,72 \pm 1,783^{\mathrm{Ab}}$ & $96,53 \pm 1,783^{\mathrm{At}}$ \\
\hline 7 dias & $62,59 \pm 1,746^{\mathrm{Ba}}$ & $63,70 \pm 1,746^{\mathrm{Ba}}$ & $56,50 \pm 1,783^{\mathrm{Bb}}$ & $55,05 \pm 1,783^{\mathrm{BL}}$ \\
\hline 14 dias & $61,09 \pm 1,746^{\mathrm{Ba}}$ & $54,84 \pm 1,746^{\mathrm{Cb}}$ & $50,38 \pm 1,783^{\mathrm{Cb}}$ & $54,20 \pm 1,746^{\mathrm{BL}}$ \\
\hline 21 dias & $47,20 \pm 1,823^{\mathrm{Ca}}$ & $45,59 \pm 1,746^{\mathrm{Da}}$ & $45,37 \pm 1,823^{\mathrm{Ca}}$ & $45,72 \pm 1,746^{\mathrm{C}_{2}}$ \\
\hline \multirow[t]{2}{*}{28 dias } & $39,53 \pm 1,746^{\mathrm{Da}}$ & $38,24 \pm 1,823^{\mathrm{Ea}}$ & $35,57 \pm 1,866^{\mathrm{Da}}$ & $26,79 \pm 1,783^{\mathrm{Dt}}$ \\
\hline & \multicolumn{4}{|c|}{ Permanência do ovo no ninho } \\
\hline Altura de albúmen & $\mathbf{0 h}$ & $2 \mathrm{~h}$ & $4 h$ & $6 h$ \\
\hline \multicolumn{5}{|c|}{ Período de armazenamento } \\
\hline 0 dia & $11,80 \pm 0,181^{\mathrm{Aa}}$ & $10,68 \pm 0,181^{\mathrm{Ab}}$ & $9,93 \pm 0,185^{\mathrm{Ac}}$ & $9,46 \pm 0,185^{\mathrm{Ac}}$ \\
\hline 7 dias & $4,37 \pm 0,181^{\mathrm{Bab}}$ & $4,51 \pm 0,181^{\mathrm{Ba}}$ & $3,96 \pm 0,185^{\mathrm{Bb}}$ & $3,78 \pm 0,185^{\mathrm{Bb}}$ \\
\hline 14 dias & $4,21 \pm 0,181^{\mathrm{Ba}}$ & $3,72 \pm 0,181^{\mathrm{Cab}}$ & $3,44 \pm 0,185^{\mathrm{Cb}}$ & $3,58 \pm 0,181^{\mathrm{Bb}}$ \\
\hline 21 dias & $3,10 \pm 0,189^{\mathrm{Ca}}$ & $3,00 \pm 0,181^{\mathrm{Da}}$ & $3,10 \pm 0,189^{\mathrm{CDa}}$ & $3,04 \pm 0,181^{\mathrm{Ca}}$ \\
\hline 28 dias & $2,55 \pm 0,181^{\mathrm{Da}}$ & $2,56 \pm 0,189^{\mathrm{Da}}$ & $2,61 \pm 0,185^{\mathrm{Da}}$ & $2,14 \pm 0,181^{\mathrm{Da}}$ \\
\hline
\end{tabular}

Médias seguidas por letras diferentes, maiúsculas na coluna e minúsculas na linha, diferem significativamente entre si pelo teste de Tukey $(\mathrm{P}<0,05)$. Fonte: Autores.

Em relação à Unidade Haugh (UH) para ovos no dia 0, os maiores valores foram registrados para ovos que não permaneceram no ninho (0h), com redução significativa a partir de quatro horas de permanência nos ninhos (4h e 6h). Os resultados obtidos no presente estudo permitem classificar os ovos avaliados no período 0 como AA, ou seja, ovos de excelente qualidade. Já para a UH aos 7 dias de armazenamento, foi observado que os ovos que permaneceram por somente 2 horas no ninho obtiveram os maiores índices; e, mais uma vez, os menores valores corresponderam aos ovos que permaneceram de quatro a seis horas no ninho ( 4 a $6 \mathrm{~h}$ ). Observando a tabela 3 , pode-se perceber que a perda de UH entre 0 e 7 dias é mais acentuada em relação aos outros períodos de armazenamento, isso se deve ao fato de que a velocidade das reações que levam à redução dos valores de UH é mais acentuada durante os primeiros dias pós-postura (Xavier et al., 2008). Até os 14 dias de armazenamento, os ovos sem exposição ao ninho (0h) ainda mantiveram maiores índices de UH, porém, pode-se observar uma tendência dos valores se igualarem entre os tempos, tendência esta que é confirmada pelos resultados obtidos no $21^{\circ}$ dia de armazenamento, onde os tempos de exposição já não influenciaram significativamente esta variável. No $28^{\circ}$ dia de armazenamento, ovos com $0 \mathrm{~h}, 2 \mathrm{~h}$ e $4 \mathrm{~h}$ de contato com o ninho, seguiram a tendência de igualdade para UH e aqueles com $6 \mathrm{~h}$ apresentaram o menor valor médio.

Como UH e altura de albúmen estão diretamente correlacionadas entre si, percebe-se comportamento similar nos resultados obtidos entre estas duas variáveis. Os maiores valores de altura de albúmen foram encontrados nos ovos sem 
exposição ao ninho (0h), seguido por ovos com 2 horas de permanência no ninho (2h). Novamente nota-se que a partir das 4 horas de exposição ao ninho há maior perda de qualidade, o que reforça o fato de que, após este período, as alterações na qualidade interna dos ovos começam a se tornar significativas. O comportamento observado para estas variáveis pode ser explicado, novamente, pelas condições térmicas e de umidade aos quais foram sujeitos os ovos nos ninhos ao longo do dia, onde ovos com 4 horas ou mais de permanência no ninho, apresentaram maiores temperaturas, tal qual os ninhos e o interior do galpão. Todos estes fatores aceleram as reações que tornam o albúmen mais liquefeito e, por consequência, resultam na diminuição da sua altura e nos valores de UH. Fanyu et al. (2014), ao trabalharem com aves da linhagem Hy-line Brown em gaiolas enriquecidas, encontraram média de $11,38 \mathrm{~mm}$ para altura de albúmen, bem próxima aos valores encontrados neste estudo para os tempos $0 \mathrm{~h}$ e $2 \mathrm{~h}$.

A influência do tempo de permanência dos ovos no ninho sobre os períodos de armazenamento pode ser observada até os 14 dias. Após este período, percebe-se que os valores tendem a se estabilizar, como observado anteriormente com a variável UH. No entanto, para a altura do albúmen, percebe-se que aos 28 dias de armazenamento, os ovos com 6 horas de contato com o ninho não apresentaram diferenças significativas em relação aos demais tempos, assim como ocorreu com a UH, fato este que pode ser atribuído ao peso dos ovos analisados, já que este fator é considerado na determinação da UH.

$\mathrm{Na}$ Tabela 4, são apresentados os resultados obtidos para a interação entre o tempo de permanência no ninho e o período de armazenamento dos ovos, para as variáveis $\mathrm{pH}$ da gema, $\mathrm{pH}$ do albúmen e substâncias reativas ao ácido tiobarbitúrico (TBARS), dada em mg MDA.kg-1 de amostra. Diante dos resultados observados, nota-se que houve interação significativa $(\mathrm{P}<0,05)$ entre os diferentes tempos de exposição dos ovos ao ninho e os períodos de armazenamento para as variáveis pH da gema e substâncias reativas ao ácido tiobarbitúrico (TBARS).

Tabela 4. Médias ( \pm desvio-padrão) obtidas para valores de $\mathrm{pH}$ da gema, $\mathrm{pH}$ do albúmen e oxidação lipídica (TBARS) (mg MDA.kg ${ }^{-1}$ de amostra) de ovos cage-free coletados até 6 horas pós-postura armazenados por até 28 dias.

\begin{tabular}{cccc}
\hline $\begin{array}{c}\text { Permanência do } \\
\text { ovo no ninho }\end{array}$ & pH Gema & pH Albúmen & TBARS \\
$0 \mathrm{~h}$ & $6,41 \pm 0,0252$ & $9,31 \pm 0,0334$ & $0,178 \pm 0,004$ \\
$2 \mathrm{~h}$ & $6,48 \pm 0,0257$ & $9,33 \pm 0,0331$ & $0,165 \pm 0,004$ \\
$4 \mathrm{~h}$ & $6,51 \pm 0,0255$ & $9,34 \pm 0,0336$ & $0,166 \pm 0,004$ \\
$6 \mathrm{~h}$ & $6,55 \pm 0,0254$ & $9,43 \pm 0,0333$ & $0,156 \pm 0,004$ \\
\hline Período de & $\mathbf{p H ~ G e m a}$ & $\mathbf{p H}$ Albúmen & TBARS \\
armazenamento & $6,37 \pm 0,0277$ & $8,94 \pm 0,037^{\mathrm{B}}$ & $0,167 \pm 0,005$ \\
0 dias & $6,68 \pm 0,0280$ & $9,53 \pm 0,037^{\mathrm{A}}$ & $0,134 \pm 0,005$ \\
7 dias & $6,23 \pm 0,0285$ & $9,53 \pm 0,037^{\mathrm{A}}$ & $0,228 \pm 0,005$ \\
14 dias & $6,51 \pm 0,0290$ & $9,54 \pm 0,037^{\mathrm{A}}$ & $0,170 \pm 0,005$ \\
21 dias & $6,67 \pm 0,0290$ & $9,52 \pm 0,037^{\mathrm{A}}$ & $0,134 \pm 0,005$ \\
28 dias & & & \\
Fonte de variação & 0,0009 & 0,0528 & 0,0192 \\
Permanência no ninho & $<0,0001$ & $<0,0001$ & $<0,0001$ \\
Armazenamento & 0,0003 & 0,8653 & $<0,0001$ \\
\hline
\end{tabular}

Médias seguidas por letras diferentes nas colunas diferem significativamente entre si pelo teste de Tukey $(\mathrm{P}<0,05)$. TBARS: substâncias reativas ao ácido tiobarbitúrico. Fonte: Autores.

Para pH do albúmen, não foram observadas interações significativas entre os tempos de permanência no ninho e os períodos de armazenamento dos ovos. Os diferentes tempos de exposição ao ninho também não influenciaram $(\mathrm{P}>0,05)$ os 
resultados para esta variável. Porém, os valores de $\mathrm{pH}$ do albúmen foram afetados $(\mathrm{P}<0,05)$ pelo período de armazenamento, sendo que os menores valores foram observados nos ovos do dia 0 . A partir do $7^{\circ}$ dia de armazenamento, os valores de $\mathrm{pH}$ de albúmen aumentaram em relação aos ovos frescos, porém, seguiram constantes $(\mathrm{P}>0,05)$ durante os demais períodos avaliados.

O pH do albúmen para ovos frescos varia entre 7,6 e 8,5 (Heath, 1977; Romanoff \& Romanoff, 1949). Para ovos armazenados, o pH do albúmen tende a aumentar de acordo com a temperatura e o período de armazenamento, alcançando valores próximos a 9,7 (Heath, 1977). Sharp e Powell (1931) encontraram valores próximos a 9,4 em ovos armazenados por 21 dias independentemente da temperatura armazenada que variou entre $3{ }^{\circ} \mathrm{C}$ e $35^{\circ} \mathrm{C}$.

$\mathrm{O}$ aumento observado nos valores de $\mathrm{pH}$ do albúmen se deve às perdas de $\mathrm{CO}_{2}$ para o ambiente através das membranas. Com o passar do tempo ocorre a dissociação do ácido carbônico, que se trata de um componente tampão do albúmen, em $\mathrm{CO}_{2}$ e água. $\mathrm{O} \mathrm{CO}_{2}$ difunde-se através da casca para o ambiente e essa perda resulta em aumento do $\mathrm{pH}$ do albúmen e dissociação do complexo proteico (Stadelman \& Cotterill, 1994).

$\mathrm{O}$ ambiente também influencia diretamente os valores de $\mathrm{pH}$ do albúmen, já que este é dependente do equilíbrio entre o dióxido de carbono dissolvido, os íons de bicarbonato, os íons de carbonato e as proteínas presentes no albúmen. As concentrações dos íons de carbonato e bicarbonato são dependentes da pressão parcial do dióxido de carbono no ambiente externo. Com o aumento na concentração de dióxido de carbono no ambiente, a concentração de íons de bicarbonato aumenta enquanto a concentração de íons de carbonato diminui, ou seja, quanto maior a concentração de $\mathrm{CO}_{2}$ no ambiente, maiores serão os valores obtidos para o pH do albúmen (Brooks e Pace, 1938).

Os valores de pH de albúmen encontrados para os ovos recém postos são maiores daqueles encontrados na literatura. Estes valores podem ser atribuídos aos maiores teores de $\mathrm{CO}_{2}$ no galpão. Shepherd et al. (2015) avaliaram diferentes sistemas de produção para aves de postura e encontraram níveis superiores de emissão de $\mathrm{CO}_{2}$ em sistemas cage-free (74 g/ave/dia) em comparação a sistemas de gaiolas convencionais (68,3 g/ave/dia). Sendo assim, neste estudo, o sistema de criação das aves pode ter resultado em maiores índices de concentração de dióxido de carbono no ambiente e, consequentemente, resultado em maiores valores médios de $\mathrm{pH}$ do albúmen dos ovos frescos em comparação aos valores já descritos na literatura.

Nas Tabelas 5 e 6, encontram-se os desdobramentos das interações entre o tempo de permanência dos ovos cage-free e o período de armazenamento para as variáveis $\mathrm{pH}$ da gema e substâncias reativas ao ácido tiobarbitúrico (TBARS), dadas em mg de malonaldeído/kg de amostra, respectivamente.

Tabela 5. Desdobramento da interação ( \pm desvio-padrão) entre o tempo de permanência dos ovos no ninho e o período de armazenamento para $\mathrm{pH}$ da gema de ovos provenientes de sistema cage-free.

\begin{tabular}{ccccc}
\hline pH gema & $\mathbf{0 h}$ & \multicolumn{2}{c}{ Permanência do ovo no ninho } \\
\cline { 2 - 5 } & & $\mathbf{2 h}$ & $\mathbf{4 h}$ & $\mathbf{6 h}$ \\
\hline Período de armazenamento & & & \\
0 dia & $6,27 \pm 0,055^{\mathrm{Bb}}$ & $6,35 \pm 0,055^{\mathrm{Bab}}$ & $6,47 \pm 0,056^{\mathrm{Ba}}$ & $6,38 \pm 0,056^{\mathrm{Cab}}$ \\
7 dias & $6,57 \pm 0,055^{\mathrm{Ab}}$ & $6,65 \pm 0,056^{\mathrm{Aab}}$ & $6,71 \pm 0,056^{\mathrm{Aab}}$ & $6,81 \pm 0,057^{\mathrm{Aa}}$ \\
14 dias & $6,20 \pm 0,057^{\mathrm{Bb}}$ & $6,18 \pm 0,057^{\mathrm{Cb}}$ & $6,16 \pm 0,057^{\mathrm{Cb}}$ & $6,38 \pm 0,056^{\mathrm{Ca}}$ \\
21 dias & $6,56 \pm 0,058^{\mathrm{Aab}}$ & $6,48 \pm 0,058^{\mathrm{Bab}}$ & $6,40 \pm 0,058^{\mathrm{Bb}}$ & $6,59 \pm 0,056^{\mathrm{Ba}}$ \\
28 dias & $6,48 \pm 0,056^{\mathrm{Ab}}$ & $6,75 \pm 0,060^{\mathrm{Aab}}$ & $6,83 \pm 0,057^{\mathrm{Aa}}$ & $6,62 \pm 0,058^{\mathrm{Bb}}$ \\
\hline
\end{tabular}

Médias seguidas por letras diferentes, maiúsculas na coluna e minúsculas na linha, diferem significativamente entre si pelo teste de Tukey $(\mathrm{P}<0,05)$. Fonte: Autores.

Para a variável pH de gema, no dia 0, pode-se notar que o tempo de permanência dos ovos no ninho influenciou de forma significativa o comportamento desta variável. Impacto maior foi observado nos ovos que permaneceram por 4 horas no 
ninho, quando o pH de gema atingiu seu maior valor, porém, sem apresentar diferenças significativas entre os ovos expostos por 2 e 6 horas ao ninho (Tabela 5). Ao passo que ovos sem contato com o ninho (0h) apresentaram menor valor de $\mathrm{pH}$ de gema e diferença significativa em relação aos ovos expostos ao ninho por 4 horas, porém, também sem diferenças significativas entre ovos expostos no ninho por 2 e 6 horas. Nos ovos que foram armazenados, também se pode observar efeito significativo dos tratamentos em todos os períodos avaliados, mais uma vez mostrando que o tempo de permanência dos ovos nos ninhos alterou a qualidade interna dos mesmos.

Shang et al. (2004) observaram que o aumento do $\mathrm{pH}$ da gema ocorre devido a migração de íons alcalinos como o sódio, potássio e o magnésio do albúmen para a gema durante o período de armazenamento, que são trocados pelos íons de hidrogênio, provocando um acréscimo no $\mathrm{pH}$ da gema. Corroborando com o estudo em questão, ao verificar que com o armazenamento prolongado, aumentaram-se os valores de $\mathrm{pH}$, indicando sútil declínio na qualidade interna dos ovos, visto que a elevação do $\mathrm{pH}$ é forte indicador da perda de qualidade do ovo. $\mathrm{O} \mathrm{pH}$ da gema de ovos frescos geralmente assume valores próximos a 6,0, podendo atingir valores mais elevados até $6,9 \mathrm{com}$ o armazenamento, sendo que, quanto maior a temperatura que os ovos estejam expostos, mais rápido se dará o aumento do $\mathrm{pH}$ e mais altos serão os valores atingidos (Alleoni \& Antunes, 2001; Ordónez, 2005; Singh \& Panda, 1990).

Já a oxidação lipídica nas gemas dos ovos avaliados foi influenciada significativamente, tanto pelo tempo de permanência dos ovos no ninho, quanto pelo período de armazenamento (Tabela 6). A maior influência para esta variável se deu aos 14 dias de armazenamento quando foram atingidos os maiores valores de TBARS, ao passo que, após esse período, os valores tenderam a diminuir. Thimótheo (2016) observou comportamento semelhante para a oxidação lipídica de ovos de aves provenientes de sistema cage-free, obtendo valores de 0,196, 0,180, 0,272, 0,198 e 0,180 mg de malonaldeído/kg de amostra para $0,7,14,21$ e 28 dias de armazenamento, respectivamente. Nos períodos de 0,7 e 28 dias o tempo de permanência dos ovos no ninho não influenciou a oxidação lipídica nas gemas.

Tabela 6. Desdobramento da interação ( \pm desvio-padrão) entre o tempo de permanência dos ovos no ninho e o período de armazenamento para oxidação lipídica (TBARS) (mg MDA.kg-1 de amostra) de ovos provenientes de sistema cage-free.

\begin{tabular}{ccccc}
\hline \multirow{2}{*}{ TBARS } & 0h & Ph & 4h & 6h \\
\cline { 2 - 5 } & & & \\
Período de armazenamento & & & \\
$0,178 \pm 0,011^{\mathrm{Ba}}$ & $0,152 \pm 0,011^{\mathrm{Ba}}$ & $0,175 \pm 0,011^{\mathrm{Aa}}$ & $0,162 \pm 0,011^{\mathrm{ABa}}$ \\
0 dia & $0,143 \pm 0,011^{\mathrm{Ca}}$ & $0,129 \pm 0,011^{\mathrm{BCa}}$ & $0,132 \pm 0,011^{\mathrm{Ba}}$ & $0,131 \pm 0,011^{\mathrm{Ba}}$ \\
7 dias & $0,268 \pm 0,011^{\mathrm{Aa}}$ & $0,277 \pm 0,011^{\mathrm{Aa}}$ & $0,200 \pm 0,011^{\mathrm{Ab}}$ & $0,165 \pm 0,011^{\mathrm{Ac}}$ \\
14 dias & $0,158 \pm 0,011^{\mathrm{BCb}}$ & $0,146 \pm 0,011^{\mathrm{BCb}}$ & $0,182 \pm 0,011^{\mathrm{Aa}}$ & $0,192 \pm 0,011^{\mathrm{Aa}}$ \\
21 dias & $0,145 \pm 0,011^{\mathrm{Ca}}$ & $0,121 \pm 0,011^{\mathrm{Ca}}$ & $0,143 \pm 0,011^{\mathrm{Ba}}$ & $0,129 \pm 0,011^{\mathrm{Ba}}$ \\
\hline 28 dias &
\end{tabular}

Médias seguidas por letras diferentes, maiúsculas na coluna e minúsculas na linha, diferem significativamente entre si pelo teste de Tukey $(\mathrm{P}<0,05)$. TBARS: substâncias reativas ao ácido tiobarbitúrico. Fonte: Autores.

A oxidação dos lipídeos, também conhecida como rancidez, é um processo natural e inevitável em alimentos e define a vida útil dos mesmos, visto que as reações químicas que resultam deste processo geram produtos indesejáveis do ponto de vista sensorial, causando alterações no sabor dos alimentos e no seu valor nutricional, pois destrói vitaminas lipossolúveis e ácidos graxos essenciais (Frankel, 1984; Cherian, 1996). Torres e Okani (1997) preconizam que valores de TBARS de até 1,59 mg de malonaldeído/kg de amostra não causam alterações nas características sensoriais e prejuízos para a saúde do consumidor, sendo assim, os valores encontrados neste estudo não demonstram prejuízo ao sabor dos ovos, visto que os valores de TBARS estão bem abaixo deste limite. 


\section{Conclusão}

O tempo que os ovos permanecem nos ninhos, entre a postura e a coleta, exerce influência negativa sobre as características qualitativas internas, tanto dos ovos frescos quanto dos ovos armazenados por até 28 dias em temperatura ambiente, o que demanda o desenvolvimento de novas técnicas de coleta e a adoção de boas práticas de manejo nas granjas avícolas, associada a um armazenamento adequado, de forma assegurar a qualidade e aumentar o tempo de prateleira do produto comercializado. Resultados esses que demonstram a importância do tempo de coleta pós-postura sobre a qualidade dos ovos provenientes de sistemas alternativos de criação, em que as aves são criadas livres de gaiolas, encorajando novos estudos sobre a temática abordada, como, por exemplo, o efeito de diferentes linhagens e idades das poedeiras comerciais sobre a qualidade física, tecnológica e microbiológica dos ovos produzidos sob estes sistemas que primam pelo bem-estar animal.

Dessa forma, visando reduzir as perdas em qualidade do produto final destinado ao mercado consumidor, sugere-se que a coleta dos ovos em sistema cage-free seja realizada o mais breve possível, preferencialmente, até 4 horas após a postura.

\section{Agradecimentos}

À Coordenação de Aperfeiçoamento de Pessoal de Nível Superior (CAPES), pela bolsa de mestrado concedida para execução do projeto.

\section{Referências}

Alleoni, A. C. C., \& Antunes, A. J. (2001). Unidade Haugh como medida da qualidade de ovos de galinha armazenados sob refrigeração. Scientia Agrícola, $58(4), 681-685$

Alves, S. P., Silva, I. J. O., \& Piedade, S. M. S. (2007). Avaliação do bem-estar de aves poedeiras comerciais: efeitos do sistema de criação e do ambiente bioclimático sobre o desempenho das aves e a qualidade de ovos. Revista Brasileira de Zootecnia, 36, 1388-1394.

Brito, D. R. N., Pereira, A. L. F., Mota, A. S. B., Freitas, E. R., \& Abreu, V. K. G. (2020). Eggs quality sold at different establishments in the Imperatriz city, Maranhão State, Brazil. Research, Society and Development, 9(9), e749997848.

Brooks, J., \& Pace, J. (1938). The distribution of carbon dioxide in the hen's egg. Proceedings of the Royal Society of London, 126(843), 196-210.

Card, L. E., \& Nesheim, M. C. (1978). Produción avícola. Editoral Acribia.

Cedro, T. M. M., Calixto, L. F. L., Gaspar, A., \& Hora, A. S. (2010). Teores de ácidos graxos em ovos comerciais convencionais e modificados com ômega-3. Revista Brasileira de Zootecnia, 39(8), 1733-1739.

Cherian, G., Wolfe, E. H., \& Sim, J. S. (1996). Dietary oils added tocopherols: effects on egg or tissue tocopherols, fatty acids, and oxidative stability. Poultry Science, 75, 423-431.

Davis, B. H., \& Stephenson, H. P. (1991). Egg quality under tropical conditions in north Queensland. Food Australian, 43, 496-499.

Dutra, D. R., Guimarães, M. F. M. do A., Villegas-Cayllahua, E. A., Mello, J. L. M. de, Souza, R. A. de, Giampietro-Ganeco, A., Ferrari, F. B., \& Borba, H. (2021). Caracterização dos componentes internos e qualidade dos ovos de perdiz brasileira (Rhynchotus rufescens) durante 28 dias de armazenamento. Research, Society and Development, 10(1), e9710111399.

Fanyu, M., Donghua, C, Xiang, L., Jianhong, L., \& Jun, B. (2014). Effects of large or small furnished cages on performance, welfare and egg quality of laying hens. Animal Production Science, 55(6), 793-798.

Frankel, E. N. (1984). Lipid oxidation: mechanisms, products and biological significance. Journal of the American Oil Chemists Society, 61, $1908-1917$.

Heath, J. L. (1977). Chemical and related osmotic changes in egg albumen during storage. Poultry Science, 55, 936-942.

Isa Hendrix Genetic Company. (2007). ISA Brown commercial management guide. Recuperado de: https://www.isa-poultry.com/en/product/isa-brown/

Jones, D. R., Tharrington, J. B., Curtis, P. A., Anderson, K. E., Keener, K. M., \& Jones, F. T. (2002). Effects of cryogenic cooling of shell eggs on egg quality. Poultry Science, 81(5), 727-733.

Leandro, N. S. M., Deus, H. A. B., Stringhini, J. H., Café, M. B., Andrade, M. A., \& Carvalho, F. B. (2005). Aspectos de qualidade interna e externa de ovos comercializados em diferentes estabelecimentos na região de Goiânia. Ciência Animal Brasileira, 6(2), 71-78.

Mendes, F. R., Leandro, N. S. M., Andrade, M. A., Cafe, M. B., Santana, E. S., \& Stringhini, J. H. (2014). Qualidade bacteriológica de ovos contaminados com Pseudomonas aeruginosa e armazenados em temperatura ambiente ou refrigerados. Ciência Animal Brasileira, 15(4), 444-450. 
Morais, C. F. A., Campos, E. J., \& Silva, T. J. P. (1997). Qualidade interna de ovos comercializados em diferentes supermercados na cidade de Uberlândia. Arquivo Brasileiro de Medicina Veterinária e Zootecnia, 49, 365-373.

Ordónez, J. A. (2005). Ovos e produtos derivados. Tecnologia de alimentos. Alimentos de origem animal. Artmed, $269-279$.

Palmer, H. H., \& Paul, C. O. (1972). Food Theory and Applications. Nova Iorque, Estados Unidos: John Wiley \& Sons, $527-561$.

Pereira A. S., Shitsuka, D. M., Parreira, F. J. \& Shitsuka, R. (2018). Metodologia da pesquisa científica. UFSM. Recuperado de: https://repositorio.ufsm.br/bitstream/handle/1/15824/Lic_Computacao_Metodologia-Pesquisa-Cientifica.pdf?sequence=1 .

Rodenburg, T. B., Tuyttens, F. A. M., Sonk, B., De Reu, K., Herman, L., \& Zoons, J. (2005). Welfare, health, and hygiene of laying hens housed in furnished cages and in alternative housing systems. Journal of Applied Animal Welfare Science, 8(3), 211-226.

Romanoff, A. L., \& Romanoff, A. J. (1949). The avian egg. Nova Iorque, John Wiley \& Sons.

Santos, M. S. V., Espíndola, G. B., Lôbo, R. N. B., Freitas, E. R., Guerra, J. L. L., \& Santos, A. B. E. (2009a). Efeito da temperatura e estocagem em ovos. Ciência e Tecnologia de Alimentos, Campinas, 29(3), 513-517.

Santos, M. S. V., Espíndola, G. B., Lôbo, R. N. B, Fuentes, M. F. F. Carvalho, L. E., \& Santos, A. B. E. (2009b). Desempenho e qualidade dos ovos de poedeiras comerciais, submetidas às dietas com diferentes óleos vegetais. Revista Brasileira de Saúde e Produção Animal, 10(3), 654-667.

SAS. Statistical Analysis Sistem. (2002). User's guide: statistics 9.0. Cary, NC: SAS Institute inc.

Scott, T. A., \& Silversides, F. G. (2000). The effect of storage and strain of hen on egg quality. Poultry Science, 79(12), $1725-1729$.

Shang, X. G., Wang, F. L., Li, D. F., Yin, J. D., \& Li, J. Y. (2004). Effect of dietary conjugated linoleic acid on productivity of laying hens and egg quality during refrigerated storage. Poultry Science, 79(12), 1775-1781.

Sharp, P. F., \& Powell, C. K. (1931). Increase the pH of the white and yolk of hen's eggs. Industry of Engineering Chemistry, $26,196-199$.

Shepherd, T. A., Zhao, Y., Li, H., Stinn, J. P., Hayes, M. D., \& Xin, H. (2015). Environmental assessment of three egg production systems. Poultry Science, 94(3), 534-543.

Siebel, N. F., \& Souza-Sorares, L. A. (2004). Efeito do resíduo de pescado sobre as características físicas e químicas de ovos de codornas armazenados em diferentes períodos. Semina: Ciências Agrárias, 25, 35-44.

Silva, I. J. O., Barbosa Filho, J. A. D., Silva, M. A. N., \& Piedade, S. M. (2006). Influência do sistema de criação nos parâmetros comportamentais de duas linhagens de poedeiras submetidas a duas condições ambientais. Revista Brasileira de Zootecnia, 35, 1439-1446.

Singh, R. P., \& Panda, B. (1990). Comparative study on some quality attributes of quail and chicken eggs during storage. Indian Journal of Animal Sciences, $60,114-117$.

Souza, P. A. (1997). Efeito da idade da galinha na qualidade dos ovos mantidos sob condições de ambiente. Ciência e Tecnologia de Alimentos. Campinas, 17, 49-52.

Stadelman, W. J., \& Cotterill, O. J. (1994). Egg Science and Technology (4a ed.). The Haworth Press.

Torres, E. A. F. S., \& Okani, E. T. (1997). Teste de TBA: ranço em alimentos. Revista Nacional da Carne, 243(5), 68-76.

UBA. União Brasileira de Avicultura. (2008). Protocolo de boas práticas de produção de ovos. São Paulo: União Brasileira de Avicultura.

USDA. (2000). Egg-Grading Manual. Washington: Departament of Agriculture.

Vyncke, B. W. (1970). Direct determination of the thiobarbituric acid value in trichloracetic acid extracts of fish as a measure of oxidative rancidity. Fette, Seifen, Anstrichmittel, 72(12), 1084- 1087.

Xavier, I. M. C., Cançado, S. V., Figueiredo, T. C., Lara, L. J. C, Lana, A. M. Q., Souza, M. R., \& Baião, N. C. (2008). Quality of consume eggs submitted to different storage conditions. Arquivo Brasileiro de Medicina Veterinária Zootecnia, 60(4), 953-959. 